\title{
The Relationship between Secondary School Students' Emotional Intelligence and Learning Motivation
}

\author{
Su-ching Lin* \\ Graduate Institute of Education, National Changhua University of Education, Taiwan \\ 1, Jin De Road, Paisha Village, Changhua City, Changhua County 500, Taiwan \\ E-mail: sclin@cc.ncue.edu.tw \\ Hui-Wen Hsieh \\ Lu-Ming Junior High School, Changhua County, Taiwan \\ No. 167, Sec. 3, Dingcao Rd., Lukang Township, Changhua County 505, Taiwan \\ E-mail: ijklopqlove@gmail.com
}

The research is financed by the Ministry of Science and Technology, Taiwan. No. MOST 108-2410-H-018-016MY2

\section{Abstract}

In recent years, emotional intelligence has been highly regarded because of its ability to control emotions, develop talented potential, build high-quality relationships, and have leadership skills. Learning motivation is the motivation of achievement in learning, a psychological need for individuals to pursue success, and also one of the main factors affecting learning achievement. Both of them are very important to young adults. However, rare studies discuss the correlation between middle school students' emotional intelligence and learning motivation. The purposes of this study were to explore the relationships between secondary school students' emotional intelligence and learning motivation. Participants were 877 secondary school students selected from central Taiwan. A questionnaire was applied to collect data. Data were analyzed by using descriptive statistics, Pearson's product-moment correlation, and multiple regression analysis. The findings of this study were as follows: First, the students' perception of the current situations of emotional intelligence and learning motivation were above a moderate level. Second, there was a positive correlation between emotional intelligence and learning motivation. Third, emotional intelligence could predict learning motivation and the level of self-motivation was the best predictor. Conclusion and discussion were also included in this study.

Keywords: Secondary school student, Emotional intelligence, Learning motivation

DOI: $10.7176 / \mathrm{JEP} / 12-5-02$

Publication date: February $28^{\text {th }} 2021$

\section{Introduction}

In recent years, emotional intelligence (EI), also known as emotional intelligence (EQ), has been highly regarded because of its ability to control emotions, develop talented potential, build high-quality relationships, and have leadership skills (Goleman, 1995, 1998). Therefore, it has been aroused a high degree of research interest. Goleman $(1995,1998)$ points out that up to $20 \%$ of life achievement is attributed to traditional intelligence (IQ), while $80 \%$ is influenced by emotional intelligence. Thus, only the traditional IQ high is not necessarily successful, but need emotional intelligence to complement each other. Segal, Smith, Robinson, and Shubin (2019) indicate emotional intelligence is very important because it will affect your performance at school or work, your physical health, your mental health, your relationships, your social intelligence.

What is emotional intelligence? Segal, Smith, Robinson, and Shubin (2019) define that emotional intelligence is the ability to understand, use, and manage your own emotions in positive ways to relieve stress, communicate effectively, empathize with others, overcome challenges, and defuse conflict. Emotional intelligence helps you build stronger relationships, succeed at school and work, and achieve your career and personal goals. It can also help you to connect with your feelings, turn intention into action, and make informed decisions about what matters most to you. In other words, emotional intelligence can be as powerful, and at times, more powerful than IQ in predicting success in various life challenges (Goleman,1995, 1998).

Recently, under the influence of the lower birth rate in Taiwan, most children are quite favored but also lack interaction with others, so children generally low resistance to pressure, fear of facing setbacks, poor behavior control. In short, they are not good at dealing with their emotions, difficult to understand the feelings of others, only concerned about their own needs have become part of the way children treat others. Especially, children in the middle stage are already in the stormy period of youth rebellion, many times the expression of emotion is direct, is reflected in the face. Due to poor emotional management and lack of emotional identification ability, they easily conflict with others, resulting in many problems. Fortunately, several studies pointed out that emotional intelligence can be improved by learning. Through learning, people will be more able to express their emotions, to have more sense of mind, and to understand social skills (Goleman, 1995, 1998; Mayer \& Salovey, 
1993). Hence, this study attempts to investigate the current situation of emotional intelligence of middle school students in Taiwan, and further through education enhance the emotional intelligence of young people, emotional management, peer-building good interaction, promote learning.

Now is the era of information explosion and rapid change of science and technology. To respond to the rapid changes in society, the content and way of education must be changed. Schooling should no longer inculcate students' unchanging knowledge, but should further teach students how to think, how to feel, how to experience, and how to learn, to cultivate students' self-study ability. Under the invasion of science and technology and the whole environment changes accelerated, learning motivation has been getting important. This generation has been faced with the "no learning, on the elimination" of the severe test. In other words, anyone must constantly learn, constantly update their knowledge, and constantly keep pace with the times, in order not to be replaced.

Learning motivation is a condition that activates and sustains behavior toward a goal. For example, children who are motivated tend to be engaged, persist longer, have better learning outcomes, and perform better than other children on standardized achievement tests (Pintrich, 2003). Stipek (1995) believes that learning motivation is the motivation of achievement in learning, a psychological need for individuals to pursue success, and also one of the main factors affecting learning achievement. Rugutt's study (2004) found that children with higher learning motivation are better shaped in their willingness to actively learn, in their high-level thinking skills, and their interaction with teachers and students. Learning motivation is also an indicator of learning progress and students' long-term learning perseverance, including goals, hard work behavior, desire to achieve goals, and positive attitude towards discussion activities, which have a great impact on learning outcomes (Berti, Mameli, Speltini, \& Molinari, 2016; Semaan \& Yamazaki, 2015). Therefore, this study attempt to survey the current situation of learning motivation of middle school students in Taiwan and further triggers their learning motivation toward active learning, absorption of new knowledge, keeping pace with the times, and continuing to move forward.

Based on literature review, the researcher found that most of the discussions on the correlative study between emotional intelligence and learning motivation focus on discussing the effects of positive and negative emotions on learning motivation, while few discuss the effects of emotional self-awareness, understanding, regulation, management, self-motivation and recognition of other people's emotions, interpersonal interaction, etc. Especially, rare studies discuss the correlation between middle school students' emotional intelligence and learning motivation. Of few studies, Cole, Feild, and Harris'study (2004) found that middle students with high emotional intelligence in the face of learning frustration and stressful events, will be a more optimistic attitude to face and make corrections and insist on completing academic achievements and learning content. In other words, students' cognition of emotional intelligence will affect their motivation to learn and their lifelong learning, which needs more studies to confirm this as a reference for further schooling. Therefore, this study wants to explore the correlation between both.

Based on the above, the research questions are discussed in this study including 1) what are the current situations of secondary school students' perceptions of their emotional intelligence and learning motivation? 2) What is the relationship between secondary school students' perceptions of their emotional intelligence and learning motivation? 3) Could secondary school students' perceptions of emotional intelligence predict their learning motivation?

\section{Methodology}

\subsection{Participants}

Participants in the current study included 877 students selected from central Taiwan including 51.40\% male students $(n=451)$ and $48.60 \%$ female students $(n=426)$. To ensure confidentiality, each survey scale was completed anonymously.

\subsection{Instruments}

Participants in the current study included 877 students selected from central Taiwan including 51.40\% male students $(n=451)$ and $48.60 \%$ female students $(n=426)$. To ensure confidentiality, each survey scale was completed anonymously.

Two instruments were used in this study. One was the Emotional Intelligence Scale (EIS) developed by Sun (2004) was administered to self-report measures assessing secondary school students' perceived emotional intelligence. EIS consisted of 27 items in five subscales, namely, understanding one's emotions (5 items), managing emotions (4 items), self-motivation (6 items), identifying the emotions of others ( 3 items), and managing interpersonal relationships (9 items). Students responded to the items on a four-point Likert scale, ranging from 1 for "strongly unconformity" to 4 for "strongly conformity". The factor analysis made on data obtained by EIS in the current application revealed that the factor load of each subject item of the EIS was greater than .45 , the value of each dimensional characteristic was between. 79 and.38, and the cumulative total 
variation was $52 \%$, indicating good validity of the items within this scale. The overall internal consistency (Cronbach's $\alpha=.87$ ) for the scale was good. The Cronbach's $\alpha$ for the five subscales ranged from .66 to .82, indicating good internal consistencies of the items within each subscale.

Another instrument was the Learning Motivation Scale (LMS) developed by Liu, Huang, Su, Chen, and Wu, (2010) was administered to self-report measures assessing students' perceived learning motivation. LMS consisted of 35 items in four subscales, namely, value ( 7 items), expectation (6 items), feeling (10 items), and will to execute (12 items). Students responded to the items on a five-point Likert scale, ranging from 1 for "strongly unconformity" to 5 for "strongly conformity". The respondents were checked according to the actual perception. The confirmatory factor analysis (CFA) made on data obtained by LMS in the current application revealed that $\chi^{2}(556, \mathrm{~N}=1101)=2867.21(\mathrm{p}<.05), \mathrm{GFI}=.87, \mathrm{AGFI}=.85 、 \mathrm{SRMR}=.04 、 \mathrm{RMSEA}=.06$, $\mathrm{CFI}=.98$ indicating good validity of the items within this scale. The overall internal consistency (Cronbach's $\alpha$ $=.96$ ) for the scale in the current sample was good. The Cronbach's $\alpha$ for the four subscales ranged from .88 to .94 , indicating good internal consistencies of the items within each subscale.

\subsection{Data Analysis}

The statistical software SPSS 20.0 for windows was used for data analysis. First of all, each subscale was computed for each respondent by adding the scores on the items in the perceived EIS and LMS respectively. Secondly, Pearson's product-moment correlation was used to examine the relationship between EIS and LMS. Finally, used multiple regression analysis to test with EIS as dependent variables and LMS as independent variables to determine if the students perceived EIS predicted perceived LMS. All statistical tests used to address the questions in this study used .05 as the minimum alpha level. The following tables presented some descriptive statistics about variables as well as highlights from the inter-correlations matrix of the variables and the results of the independent sample t-test, and multiple regression analysis runs in this study.

\section{Results}

3.1 Secondary students' perceptions of current situations of emotional intelligence and learning motivation

EIS consisted of 27 items in five subscales. Students responded to the items on a four-point Likert scale, ranging from 1 for "strongly unconformity" to 4 for "strongly conformity". Table 1 indicated that the mean score of emotional intelligence in each dimension perceived by students was above a moderate level. Of the five dimensions in emotional intelligence, the mean score of "managing emotions" (mean=3.02) was highest, followed by "understanding one's emotions" (2.99), "managing interpersonal relationships" (2.73), "identifying the emotions of others" (2.69) and "self-motivation" (2.67).

Table 1 mean and standard deviations of the emotional intelligence $(\mathrm{n}=877)$

\begin{tabular}{lcc}
\hline subscale & $\mathrm{M}$ & $\mathrm{SD}$ \\
\hline understanding one's emotions & 2.99 & 0.48 \\
managing emotions & 3.02 & 0.68 \\
self-motivation & 2.67 & 0.63 \\
identifying the emotions of others & 2.69 & 0.76 \\
managing interpersonal relationships & 2.73 & 0.55 \\
overall & 2.82 & 0.40 \\
\hline
\end{tabular}

LMS consisted of 35 items in four subscales. Students responded to the items on a five-point Likert scale, ranging from 1 for "strongly unconformity" to 5 for "strongly conformity". Table 2 indicated that the mean score of learning motivation in each dimension perceived by students was above a moderate level. Of the four dimensions in learning motivation, the mean score of "value" (mean=3.58) was highest, followed by "expectation" (mean=3.12), "will to execute" (mean=2.96), "feeling" (mean=2.94).

Table 2 mean and standard deviations of the learning motivation $(\mathrm{n}=877)$

\begin{tabular}{lll}
\hline subscale & $\mathrm{M}$ & SD \\
\hline value & 3.58 & 0.78 \\
expectation & 3.12 & 0.75 \\
feeling & 2.94 & 0.80 \\
will to execute & 2.96 & 0.80 \\
overall & 3.15 & 0.64 \\
\hline
\end{tabular}

\subsection{The correlation between students' perceived emotional intelligence and learning motivation}

Table 3 showed the inter-correlations between EIS and LMS. The five EIS subscales and four LMS subscales significantly correlated with each other indicating the higher score at emotional intelligence, the higher score at learning motivation. Table 3 also showed the overall and four subscales of EIS had the middle positive correlation with overall and five subscales of LMS. Of the correlations between subscales of EIS and overall of 
LMS, the highest correlations coefficient is identifying the emotions $(r=.47, p<.001)$, followed by "understanding one's emotions" ( $r=.46, p<.001)$, "managing emotions" $(r=.37, p<.001)$, "self-motivation" $(r=.22, p<.001)$, and "managing interpersonal relationships" $(r=.18, p<.001)$.

Table 3 Summary of correlation analysis between emotional intelligence and learning motivation

\begin{tabular}{lccccc}
\hline \multirow{2}{*}{\multicolumn{1}{c}{ EIS }} & \multicolumn{5}{c}{ LMS } \\
\cline { 2 - 6 } & value & expectation & feeling & will to execute & overall \\
\hline understanding one's emotions & $.38^{* * *}$ & $.37^{* * *}$ & $.37^{* * *}$ & $.37^{* * *}$ & $.46^{* * *}$ \\
managing emotions & $.34^{* * *}$ & $.29^{* * *}$ & $.29^{* * *}$ & $.29^{* * *}$ & $.37^{* * *}$ \\
self-motivation & $.19^{* * *}$ & $.25^{* * *}$ & $.19^{* * *}$ & $.10^{* * *}$ & $.22^{* * *}$ \\
identifying the emotions of others & $.38^{* * *}$ & $.38^{* * *}$ & $.40^{* * *}$ & $.39^{* * *}$ & $.47^{* * *}$ \\
managing interpersonal relationships & $.13^{* * *}$ & $.17^{* * *}$ & $.11^{* *}$ & $.19^{* * *}$ & $.18^{* * *}$ \\
overall & $.23^{* * *}$ & $.12^{* * *}$ & $.26^{* * *}$ & $.26^{* * *}$ & $.27^{* * *}$ \\
\hline
\end{tabular}

${ }^{* *} p<.01{ }^{* * *} p<.001$

\subsection{The prediction of learning motivation from emotional intelligence}

Multiple regression analyses were also performed to take advantage of our large sample size $(\mathrm{n}=877)$. Each of the multiple regression analyses performed had an LMS measure as the dependent measure. Predictor variables included scores of understanding one's emotions, managing emotions, self-motivation, identifying the emotions of others, and managing interpersonal relationships. Table 4 indicated $F(5,871)=60.78, p$-value $<.001$, and $R=.51$, the $R^{2=} .26$. That is, EIS could explain $26 \%$ of the variance in perceived LMS. Further, three predictor variables, understanding one's emotions, $\beta=.16, t(871)=4.54, p<.001)$, managing emotions $(\beta=.11, t$ $(871)=3.72, p<.001)$; and self-motivation $(\beta=.36, t(871)=9.64, p<.001)$ could significantly predict students' LMS. The self-motivation was the best predictor.

Table 4 Summary of the multiple regression analysis of emotional intelligence to overall learning motivation

\begin{tabular}{|c|c|c|c|c|}
\hline & criterion variables & & & \\
\hline predictor variables & $\mathrm{B}$ & SD & $\beta$ & $t$ \\
\hline understanding one's emotions & 0.21 & .05 & .16 & $4.54^{* * *}$ \\
\hline managing emotions & 0.11 & .03 & .11 & $3.72^{* * *}$ \\
\hline self-motivation & 0.36 & .04 & .36 & $9.64^{* * *}$ \\
\hline identifying the emotions of others & 0.02 & .03 & .03 & 0.91 \\
\hline managing interpersonal relationships & 0.01 & .04 & .01 & 0.17 \\
\hline$F(5,871)$ & \multicolumn{4}{|c|}{$60.78^{* * *}$} \\
\hline$R$ & \multicolumn{4}{|c|}{.51} \\
\hline$R^{2}$ & \multicolumn{4}{|c|}{.26} \\
\hline Adj. $R^{2}$ & \multicolumn{4}{|c|}{.26} \\
\hline
\end{tabular}

$n=877 ;{ }^{* * *} p<.001$

\section{Conclusion and Discussion}

This study aimed to investigate the relationship between secondary school students' perceptions of emotional intelligence and learning motivation. Participants were 877 secondary school students selected from central Taiwan. The findings of this study were as follows: First, the emotional intelligence perceived by students was at a moderate level. The result is similar to the studies conducted by Peng (2009) and Zhang (2013). Of the five dimensions in emotional intelligence, the mean score of "managing emotions" was highest in this study. This result is also similar to the studies conducted by Peng (2009) and Zhang (2013). In terms of learning motivation, students' perceived current situation of learning motivation was moderate level. The result is similar to the study conducted by Huang (2014). Of the four dimensions in learning motivation, the mean score of "value" was the highest. This result is also similar to the studies conducted by Huang (2014) indicating that secondary school students' perceptions of the overall emotional intelligence and learning motivation in Taiwan have not changed very much even though survey participants are different.

Second, there is a medium positive correlation between students' perceptions of emotional intelligence and learning motivation. It shows that the higher the emotional intelligence perception of students, the higher their learning motivation. This result is similar to the study conducted by Sun (2004). A possible reason for this result is that Students with higher emotional intelligence can stay committed to their stated goals without being influenced by negative emotional factors. In other words, students with higher emotional intelligence can withstand learning setbacks, face learning blind spots optimistically and correct, and are willing to accept higher 
challenges.

Third, of emotional intelligence, three predictor variables, understanding one's emotions, managing emotions, and self-motivation can significantly predict students' learning motivation. Self-motivation is the best predictor. Based on Goleman's opinion (1995), self-motivation is self-efficacy, enthusiasm, optimism, and hope to reach the goals. In other words, self-motivated students can effectively strengthen their learning motivation, bear the frustration of learning, will also be more willing to break their learning setback, pursue higher-level challenges. Pintrich, Smith, and Mckeachie (1991) said, positive emotions trigger a stronger motivation for learners to learn. Some future research suggestions in this study include the following. First, use a mixed-method to collect data to learn more about the factors contributing to the results. Second, the participants in this study only were selected from central Taiwan, that the representatives are limited and unable to generalize to other regions. Hence, Future research could extend the samples of research from other counties, cities, or other countries.

\section{References}

Berti, C., Mameli, C., Speltini, G., \& Molinari, L. (2016). Teacher justice and parent support as predictors of learning motivation and visions of a just world. Issues in Educational Research, 26(4), 543-560.

Cole, M. S., Feild, H. S., \& Harris, S. G. (2004). Student learning motivation and psychological hardiness: Interactive effects on students' reactions to a management class. Academy of Management Learning \& Education, 3(1), 64-85.

Goleman, D. (1995). Emotional intelligence: Why it can matter more than IQ. New York, NY: Bantam

Goleman, D. (1998). Working with emotional intelligence. New York: Bantam Books.

Huang, W. -T. (2019). The study of the relationship between perseverance, learning motivation and learning input among Taiwanese middle school students (unpublished master's thesis). National Changhua University of Education, Changhua County. Taiwan.

Liu, Z. -H., Huang, B. -S., Su, J. -L., Chen, X. -Z., \& Wu, Y. -C. (2010). The study of the compilation, reliability, and variability of the "Elementary School and Middle School Students' Learning Motivation Scale". Journal of Testing, 57 (3), 371-402.

Mayer, J. D., \& Salovey, P. (1993). The intelligence of emotional intelligence. Intelligence, 17, 433442.

Peng, Q. -H. (2009). Research on parenting style, emotional intelligence and self-regulating learning of Taiwanese middle school students (unpublished master's thesis). National Changhua University of Education, Changhua County. Taiwan.

Pintrich, P. R. (2003). Motivation and classroom learning. Handbook of psychology, 103-122.

Pintrich, P. R., Smith, D. A. F., Garcia, T., \& McKeachie, W. J. (1991). A manual for the use of the Motivated Strategies for Learning Questionnaire (MSLQ). MI: National Center for Research to Improve Postsecondary Teaching and Learning.

Rugutt, J. (2004). Linking individual and institutional factors to motivation: A multilevel approach. Journal of Educational Research \& Policy Studies, 4(2), 52-89.

Segal, J., Smith, M., Robinson, L., \& Shubin, J. (October 2020). Improving Emotional Intelligence (EQ). retrieved from https://www.helpguide.org/articles/mental-health/emotional-intelligence-eq.htm

Semaan, G., \& Yamazaki, K. (2015). The relationship between global competence and language learning motivation: An empirical study in critical language classrooms. Foreign Language Annals, 48(3), 511-520.

Stipek, D.(1995).Effects of different instructional approaches on young children's achievement and motivation. Child Development, 66(1), 209-223.

Sun, Y. -Z (2004). Relationship between the quality of attachment, emotional intelligence and adaptation of adolescents (unpublished master's thesis). National Zhongshan University, Kaohsiung City.

Zhang S. -Y. (2013). Study on the relationship between parenting style, emotional intelligence and school life adaptation of middle school students in Taiwan. (unpublished master's thesis). National Changhua University of Education, Changhua County. Taiwan. 